\title{
Fronteiras criminais no Nazismo: lei e moral nos julgamentos de Konrad Morgen
}

\author{
Jaqueline Uzai Tavares *
}

DOI: 10.11606/issn.2318-8855.v9i1p370-399

Resumo: O propósito do presente artigo é propor uma análise para a relação entre moralidade e legalidade nos registros criminais e testemunhos do juiz Konrad Morgen, um oficial da SS que trabalhou julgando crimes cometidos pelos membros da organização em Campos de Concentração. Atráves da leitura dos registros do julgamento conduzido por ele em Buchenwald em 1944 e de seus testemunhos para o Tribunal de Nuremberg, busca-se mapear os acusados, os condenados e as justificativas mobilizadas pela SS. A análise revela que a violência, a corrupção e a insurbornição não explicam completamente o julgamento, uma vez que essas práticas eram amplamente disseminadas e raramente julgadas. Neste sentido, o tribunal tem a função de delimitar referencias jurídicos e morais para o estabelecimento de fronteiras criminais que, simultaneamente, condenam invíduos e absolvem o sistema. Morgen é uma engrenagem político-ideológica deste mecanismo de auto-reprodução da SS, que materializa um exemplo de duas ambíguas relações do regime - com a lei e com os princípios que a embasam. Seus casos são interessante ponto de partida para ponderar como esses elementos eram articulados dentro do aparato ideológico nazista - algo particularmente importante quando tratando de um período histórico cujo peso memorial e moral é manifesto.

Palavras-chave: Nazismo, Konrad Morgen, moralidade, crimes de guerra

\footnotetext{
* Graduanda em História pela Universidade de São Paulo, orientada na iniciação científica pelo profesor
} José Antonio Vasconcelos. E-mail para contato: j.u.tavares@usp.br 
Fronteiras criminais no Nazismo: lei e moral nos julgamentos de Konrad Morgen

\section{História e memória de um paradigma moral}

Dentre todos os temas históricos evocados pelo debate político contemporâneo, talvez nenhum seja tão moralmente significativo quanto o Nazismo. Trazê-lo à tona é referir-se a um dos mais discutidos e polêmicos episódios da história para a sociedade ocidental atual, um paradigma à barbaridade política do século XX.

A comoção moral gerada pelos horrores perpetrados pelo regime influencia profundamente tanto a memória social como a historiografia. O ônus de seus crimes, especialmente do Holocausto, é patente. Com tratamentos midiáticos e retóricos que oscilam entre o sensacionalismo, o tabu e a máxima repulsa, a história do nazismo pode gerar qual coisa, exceto indiferença. Mesmo posições negacionistas que vão de encontro a essa imagem hegemônica negativa emergem dessa bagagem memorial, se contrapondo justamente ao fato consumado deste ter sido um regime genocida.

Tal imagem vilanesca deriva tanto da realidade histórica como de seus registros, bem como do local em que ela se desenrolou, no coração da Europa, o que the rende ainda mais foco em meio à violência generalizada de fins do século XIX e meados do XX. Falar sobre nazismo é trazer à luz o grande crime contra a humanidade, cuja carga simbólica negativa é tão densa que ganha vida própria em alguns momentos, tornando-se um sinônimo do indesejável. ${ }^{1}$

Diante de toda essa bagagem simbólica, os sentidos morais subterrâneos de

\footnotetext{
${ }^{1}$ Um exemplo disso é o Reductio Ad Hitlerum - falácia, conceituada originalmente por Leo Strauss, que consiste na tentativa de invalidar a opinião de alguém comparando-a com a visão de Hitler ou dos nazistas sobre o mesmo assunto. $O$ nazismo se torna quase uma figura de linguagem, no qual o sentido histórico de sua violência é instrumentalizado contra algum objeto específico - a despeito da validade efetiva da comparação em questão.
} 


\section{artigos}

Jaqueline Uzai Tavares

nossas visões sobre o passado, sempre presentes, se manifestam de maneira muito explícita. Como argumenta Martin Broszat no Plea for the historicization of National Socialism:

“[...] Nacional Socialismo funciona como uma espécie de indispensável arquétipo negativo para educação civil e como um antiexemplo para a ordem política baseada na liberdade, na paz e no Estado de Direito [....." (BROSZAT, 1990, p.77) ${ }^{2}$

O caráter negativo do nazismo é exemplar, antagonista de uma série de virtudes políticas específicas. Ao mesmo tempo, porém, ele funciona como uma espécie de sinônimo abstrato da perversidade moral, como demonstra o Reductio Ad Hitlerum que, ainda que falacioso, é um recurso retórico que parte da consciência do peso que uma comparação que o nazismo possui.

Na medida que se pode afirmar que exista alguma normalidade na história e na memória, este não é um assunto normal. Essas impressões deixam um lastro quando nos debruçamos sobre o passado. Se o juízo do historiador sempre influencia suas análises sobre a história, ignorá-lo aqui é explicitamente impossível - e perigosamente imoral, tanto pelo risco de negacionismo ou de uma espécie de falsa neutralidade, como porque se faz necessária a consciência do peso argumentativo que tal referência traz. Seja aproximando ou afastando outros movimentos políticos do nazismo, o uso da história e da memória sobre o período é sempre profundamente moralizado, tanto como argumento ou como quanto falácia. Nas palavras de Charles Maier:

“[...] O Nazismo, afinal, fornece um dos básicos exemplos da maldade política.

\footnotetext{
${ }^{2}$ No original: "[...] National Socialism functions as a kind of indispensable negative standard for civic education and as the antimodel for a political order based on freedom, peace, and the rule of the law [...]". Tradução da autora.
} 


\section{artigos}

\section{Fronteiras criminais no Nazismo: lei e moral nos julgamentos de Konrad Morgen}

Como nós definimos sua ideologia ou analisamos seu sistema de governo, como nós categorizamos sua violência homicida, a quem nós atribuímos sua chegada e permanência no poder, atestam para nossas válvulas políticas subjacentes. [...]" (MAIER, 1993, p.XI). ${ }^{3}$

Contudo, a constatação dessa dimensão valorativa acerca do tema não implica em aceitá-la acriticamente, uma vez que a explicação baseada em um tabu não é capaz de gerar uma complexa narrativa ou um verdadeiro debate. Partindo da consciência dessa particularidade, ainda se mostram necessárias explicações para o inexplicável. Os inconcebíveis crimes foram, de fato, concebidos. Possuíam uma lógica interna e um sistema de valores próprios, responsáveis, ao menos, pela sua manutenção. ${ }^{4}$

A dimensão memorial e moral do tema tem sido intensamente debatida dentro da historiografia sobretudo desde os anos 1980, com destaque para os trabalhos de Martin Broszat e Saul Friedländer. Trataram-se os limites da historicização, a importância da história social, os perigos da relativização que flerta com o negacionismo, o papel da diversidade de estudos micro e macro históricos e a dificuldade de tratar discussões metodológicas em um tema tão sensível. Dentro dessa nova miríade de estudos, a agência dos carrascos tem ganhado cada vez mais espaço (CAZENAVE, 2005, p. 8). Neste quadro, Konrad Morgen foi bastante estudado por

\footnotetext{
${ }^{3}$ No original: “[...] Nazism, after all, provides one of the basic examples of political evil. How we define its ideology or analyze its system of governance, how we categorize its murderous violence, to whom we attribute it's coming to power and support, testify to our underlying political valves. [...]". Tradução da autora.

${ }^{4}$ Entende-se lógica aqui como uma maneira particular de raciocínio, ainda que essa contenha contradições. Não cabe a busca por uma falsa neutralidade que olhe para tal forma de raciocínio ignorando quão disparatado ele possa nos parecer, mas é importante ressaltar a existência de um conjunto de princípios, valores e pressupostos que conformavam o pensamento e ação nazistas, e que teve resultados efetivos - ainda que nefastos.
} 


\section{artigos}

\section{Jaqueline Uzai Tavares}

teóricos e filósofos do direito, mas poucos trabalhos historiográficos tratam de seus casos, bem como de seu papel dentro da estrutura nazista.

A análise da moral de um dos temas mais moralizados na memória contemporânea tem um certo sentido metalinguístico. A história da moral nazista é indissociável da nossa memória moral sobre o nazismo - seja como componente motivador da pesquisa ou como fonte inconsciente de nossas próprias angústias acerca do objeto de estudo.

É diante deste quadro historiográfico e memorial que o presente artigo apresenta como objetivo a análise do maior julgamento conduzido por SS Konrad Morgen, mapeando as justificativas apresentadas para a condenação dos criminosos e relacionando-as ao próprio contexto de violência dos campos de concentração. Para isso, o texto se divide em quatro partes além desta introdução. A primeira tratará de um panorama acerca da lei no regime nazista. A seguinte, das peculiaridades dos tribunais da SS e da relação de Morgen com eles. A terceira do próprio caso, e a última retomará todos esses pontos, reconectando-os à ideologia nazista e pensando seu papel na manutenção do poder e da violência do regime.

\section{O Estado Dual}

O estudo da moral nazista, principalmente no caso de Morgen, não pode ser separado da questão legal. Não havia, pois, um código penal fixo na SS, sob o qual o juiz trabalhasse. Vagamente baseada no código penal civil e no sistema dos tribunais militares, as cortes da SS dependiam sobretudo da interpretação dos juízes acerca da ética e da justiça (PAUER-STUDER e VELLEMAN, 2015, pp. 18-19). Suas bases legais são as virtudes buscadas pelo partido: defesa da comunidade, a honra, lealdade e raça (PAUER-STUDER, 2012, p. 371). 


\section{artigos}

Fronteiras criminais no Nazismo: lei e moral nos julgamentos de Konrad Morgen

Nesta situação, portanto, a lei reflete os valores intrínsecos - ao menos em tese - defendidos pela SS. Podemos derivar desta constatação duas observações. A primeira é que, como um braço central e profundamente ideologizado do Partido, essa legislação interna reflete princípios muito caros ao nazismo. Em segundo lugar, é preciso considerar o contexto de aplicação da legislação em análise: os campos de concentração. Essa busca pela virtude e pela legalidade em um dos cenários mais nefastos da guerra coloca como demanda compreender de que forma esta violência cometida pelo Regime ocorria através ou apesar da lei. Afinal, a despeito de quão estranha ela nos pareça, havia uma legislação.

Essa ambígua relação com a lei não é exclusividade dos Tribunais da SS. Foi descrita por Ernst Fraenkel em The Dual State: a Contribuition to the Theory of Dictatorship já em 1941, ou seja, antes que fosse conhecida a plena extensão da violência nazista levada a cabo nos campos de concentração e todo o sistema legal a eles emaranhado. O Regime Nazista, como colocado pelo autor, era composto não por um, mas por dois estados em constante relação e conflito: o normativo, que estabelecia as leis, e o prerrogativo, que as transgredia. Sua capacidade de atuação era delimitada pela esfera prerrogativa, sob comando do partido, ainda que o princípio da lei pertencesse ao estado normativo. (FRAENKEL, 2017, p. 57).

Na obra, Fraenkel ressalta o papel do estado normativo na manutenção da ordem econômica capitalista. É possível, porém, repensar essa dualidade também como um recurso argumentativo a ser usado no interior do próprio partido. Se apropriando do pré-estabelecido Rechsttat e do respeito à lei como algo positivo, o discurso nazista o instrumentaliza. O regime, mesmo desprezando e rejeitando parcialmente a tradição legalista, a invoca quando necessita da legitimidade que ela 


\section{artigos}

\section{Jaqueline Uzai Tavares}

ainda possui. Agir em nome desta lei é, portanto, não apenas uma forma de organização, mas uma virtude política.

As nuances dessa relação particular entre ideologia e legislação se mostram ainda mais curiosas nos tribunais da SS, onde, afinal, os mais nazistas dos nazistas julgavam seus iguais. Como dispositivo interno da organização, eles não são uma mera ferramenta de propaganda, ou um recurso organizativo da ordem econômica capitalista $^{5}$, mas uma materialização do sentido simbólico dessa lei e, portanto, do papel da própria moral no interior da ideologia nazista.

\section{Jurisdição para um massacre}

Konrad Morgen foi membro da SS de 1933 a 1945. Apesar de suas divergências com o grupo, sobretudo no que toca às suas práticas genocidas ${ }^{6}$, manteve-se como uma figura de prestígio, mesmo com pontuais recolocações. ${ }^{7}$ Possuía capacidade para

\footnotetext{
${ }^{5}$ Ainda que o fator econômico não possa ser excluído, e seja de fato um entrave que a violência generalizada e o homícido não planejado oferecia ao uso da mão de obra escrava nos Campos de Concentração (CAZENAVE, 2005, p. 32), as demandas capitalistas não se aplicam da mesma forma nesta situação nos casos civis trazidos por Fraenkel - porque a manutenção da normalidade se refere aqui sobretudo aos acusados e menos as vítimas, mortas e despossuídas de praticamente qualquer garantia em vida.

${ }^{6}$ Morgen testemunha a Nuremberg seu transtorno após visitar Auschwitz e ver com os próprios olhos o extermínio lá levado a cabo (ainda que se possa ter como praticamente certo que ele já sabia do que estava em marcha, uma vez que tinha um cargo relativamente alto dentro da SS). São notáveis as passagens do testemunho em que ele afirma sua limitação em atuar juridicamente contra o alto escalão e considera o movimento extralegal de assassinar Hitler, antes de descartá-lo pela impossibilidade prática de sua execução. Ainda que seja preciso questionar quanto dessa narrativa é construída para agradar os ouvintes do Tribunal, é possível contrastá-la com o que é dito pelo juiz nesse mesmo contexto em defesa dos Nazistas.. (In PAUER-STUDER, Herlinde e VELLEMAN, David J., Konrad Morgen: The Conscience of a Nazi Judge, pp. 87 a 91).

7 Pode-se citar também a remoção do juíz do seu posto por Himmler subitamente no meio de uma investigação, sintoma de atritos pontuais entre o trabalho de Morgen e os interesses do núcleo da organização (In MORGEN, Konrad. Affidavit concerning a German investigation of Oswald Pohl and August Frank on suspicion of mishandling funds during the war, p. 6)
} 


\section{artigos}

Fronteiras criminais no Nazismo: lei e moral nos julgamentos de Konrad Morgen negociar com oficiais e outros membros (MORGEN, 1946a, p. $83^{8}$ ), trabalhando sob o aval de Himmler (MORGEN, 1946a, p. 88). SS-Obersturmbannführer Konrad Morgen era tenente-coronel e trabalhou 12 anos para o mais politicamente engajado braço das forças paramilitares do regime. Ele era parte de um sistema, um juiz nazista, com todos os significados que ambos os termos carregam.

A relação entre o juiz e a organização é bastante ambígua, oscilando entre reprovações pontuais e contínuo suporte. Ele testemunhou no Tribunal de Nuremberg acerca dos crimes dos membros da SS cometidos em nome da organização - para a qual Morgen também trabalhava. Uma situação peculiar, que pode nos fazer questionar quão confiável seu testemunho é, sobretudo a forma pela qual ele se coloca diante dessas mesmas violências. Suas críticas ao nazismo são uma concessão às forças aliadas em uma tentativa de parecer menos terrível, tal como os relatos falsos o são para minimiza a violência da organização a qual ele servia? Não é possível determinar com clareza o que é ingênuo e o que é mentiroso.

Ainda que seja importante colocar tais observações para que tenhamos um olhar crítico sobre as fontes em análise, o relato de Morgen permanece sendo um caminho para tentar reconstruir a autoimagem do regime e elucidar algumas características do tribunal da SS, observando-as pelos julgamentos e justificativas colocados pelo juiz.

Em primeiro lugar, para Morgen, a ilegalidade e imoralidade dos casos são consequências da ação de indivíduos, não de uma prática sistêmica (PAUER-STUDER, VELLEMAN, 2015, p. 122). Esse é um ponto central para explicar como Morgen vê de maneira tão negativa os criminosos julgados e, ao mesmo tempo, permanece

\footnotetext{
${ }^{8}$ Nas citações das fontes, utilizou-se a numeração das páginas do documento original, encontradas na parte inferior dos materiais.
} 


\section{artigos}

\section{Jaqueline Uzai Tavares}

trabalhando para a organização responsável pela prática generalizada de crimes idênticos. Se a responsabilidade é exclusiva do indivíduo e é dela que emerge o caráter moralmente reprimível da violência, a SS então transcende esse julgamento. A maldade é consequência de sujeitos degenerados, não de um projeto político.

A origem de tal posicionamento pode ser atribuída a um certo cinismo legalista. A lei em é tomada como recurso suficiente para defesa da moral, da ordem social e da justiça, sem nenhum questionamento acerca de seu conteúdo e das consequências de sua aplicação. É possível refletir, porém, se não é também resultado da limitada capacidade de ação de Konrad Morgen. Sua postura diante da máquina genocida é exemplo. Se a resistência e desaprovação do juiz parecem risíveis uma vez que ele permanece na SS até seu fim, é fato que ele não poderia simplesmente processar (ou assassinar) Hitler ou Himmler. Se a ambiguidade dos testemunhos de Morgen a Nuremberg traz a postura defensiva do burocrata de uma instituição paramilitar genocida, carrega também o desamparo de quem assistiu de perto um massacre sem poder efetivamente se opor a ele. Morgen fez muito pouco, mas não havia muito que ele pudesse fazer. Sua posição é um exemplo do tensionamento entre a agência dos oficiais e a pressão exercida pela estrutura ideológica-política que eles próprios alimentavam.

Esses conflitos internos e dilemas não antagonizam plenamente o juiz à organização a qual servia, porém. Para ele, a SS não é essencialmente ruim. A violência brutal por ela praticada seria uma degeneração de seus princípios, e não consequência de sua aplicação, ainda que a exceção ocorra de maneira generalizada. (PAUER-STUDER e VELLEMAN, 2015, pp. 120-121). Tratando, por exemplo, da problemática dos experimentos com prisioneiros em campos de concentração, afirma 


\section{artigos}

\section{Fronteiras criminais no Nazismo: lei e moral nos julgamentos de Konrad Morgen}

“[...] O meu objetivo era restringir as experiências perigosas ao círculo de pessoas sob uma sentença de morte legal e a voluntários. (MORGEN, 1947c, p. 53) ${ }^{9}$

Morgen critica os experimentos conduzidos fora destes critérios, mas não questiona a situação que gera voluntários ou condena pessoas à morte, ou o próprio fato de que estes são prisioneiros, submetidos continuamente às condições insalubres, que não foram parar nos campos por acaso ou acidente. A desumanidade que ele vê nos criminosos não é generalizada ao contexto que configurou seus colegas de trabalho em carrascos e gerou a condição dos prisioneiros como tal.

A ausência das críticas sistêmicas leva à neutralização da responsabilidade política do assassinato, gerando um afastamento entre os crimes isolados e o homicídio industrial conduzido pela SS no mesmo período. Ainda que Buchenwald não fosse um campo de extermínio, as mortes nos campos de concentração eram comuns. Para Morgen, porém, não se trata do mesmo tipo de situação:

“[...] Nesse contexto, a distinção com relação à causa deve estar entre: a) Força maior; b) comandos supremos; c) Atos dissociados de indivíduos por motivos criminais. Como força maior no sentido do mal pelo qual a administração local não era responsável, também são considerados: as consequências da superlotação nos campos, o surto de doenças e epidemias, o tempo geralmente gasto no transporte dos presos em conexão com suas tarefas ou transferência e atrasos na entrega de bens de vital importância. Em virtude dos comandos supremos, as ordens transmitidas através de canais de comando diretos de Himmler, Mueller ou Pohl, a um agente designado, comprometido com sigilo especial, ocorreram: 1. Execuções em massa, principalmente

\footnotetext{
${ }^{9}$ No original, "[...] It was my aim to have the dangerous experiments restricted to the circle of persons under a lawful death sentence and to volunteers. [...]". Tradução da autora
} 


\section{artigos}

\section{Jaqueline Uzai Tavares}

por gás ems campos especiais de extermínio, 2. Execuções de indivíduos e de certos grupos de indivíduos, 3. Experiências biológicas, 4. Maus tratos e torturas destinadas a extrair declarações. (MORGEN, 1946a, p. 86). ${ }^{10}$

A força maior abstém as mortes causadas por fome, tortura, excesso de trabalho, péssimas condições sanitárias, doenças e experimentos médicos, que não são responsabilidades diretas de ninguém. Aquelas resultantes do supremo comando não são ilegais, uma vez que consistem em ordens (ainda que Morgen não pareça muito confortável em obedecê-las, dada sua suposta ideia de assassinar Hitler ou Himmler). A terceira categoria de atos individuais são os efetivamente criminosos, a maioria dos quais, porém, nunca foi a julgamento.

A postura condescendente de Morgen é um sintoma de seu alinhamento com a SS que, ainda que parcial, sobrevive a guerra. Ela reflete uma atenção da organização em categorizar a violência por ela cometida e, através deste movimento, abster-se da responsabilidade de parte dela. Efetivamente, as "mortes por causa maior" são inocentadas a partir do momento em que são postas como naturais. Que poderiam os oficiais fazer? A diferenciação se encaixa, sobretudo, quando trabalhamos os homicídios comandados e aqueles cometidos por livre iniciativa, uma vez que a lealdade e a honra são critérios a serem seguidos e, portanto, a obediência dos SS a

\footnotetext{
${ }^{10}$ No original, "[...] In this connection distinction with relation to cause must be between: a) Force majeure; b) Supreme commands; c) Separate acts of individuals from criminal motives. As force majeure in the sense of evil for which the local administration was not responsible, are too considered: the consequence of the overreading in the camps, the outbreak of diseases and epidemics, the usually long time taken in transporting the prisoners in connection with their assignment or transfer, and delays in the delivery of vitally necessary goods. By virtue of the supreme commands, orders transmitted through direct channels of command from Himmler, Mueller or Pohl, to a designated agent, who was pledged to special secrecy, there took place: 1. Mass executions, particularly by gas in special extermination camps, 2. Execution of individuals and of certain groups of individuals, 3. Biological experiments, 4. III-treatments and tortures aimed at extracting statements.[...]". Tradução da autora.
} 


\section{artigos}

Fronteiras criminais no Nazismo: lei e moral nos julgamentos de Konrad Morgen seus superiores.

Tal conclusão, porém, ainda traz dois problemas. Primeiramente, ainda que os julgamentos conduzidos por Morgen aqui analisados não tenham sido os únicos e à época foram exemplares para tentar reduzir a violência arbitrária (em um período da guerra em que as perdas de prisioneiros aptos para trabalhar estavam se tornando um problema) (CAZENAVE, 2005, p. 32), os crimes julgados não são excepcionais, uma vez que a brutalidade arbitrária sempre fora difundida - e teoricamente, sempre proibida.

Como trazido por Eugene Kogon em The Theory and Practice of Hell, um dos primeiros relatos de campos de concentração e referente a Buchenwald, a disparidade entre a violência teoricamente controlada e a real brutalidade da SS era gritante.

“ [...] Teoricamente o escritório geral do campo deveria solicitar confirmação de Berlim quando punição corporal estava para ser aplicada, e o médico do campo deveria certificar que o prisioneiro estava com boa saúde. Até o fim, porém, o procedimento difundido em muitos campos era que o prisioneiro fosse levado imediatamente para ser chicoteado, e quando a autorização chegava de Berlim, o castigo era repetido, dessa vez "oficialmente"11 (KOGON, 1950, p.104)

Já existiam regras acerca da punição corporal tanto nos primeiros anos do campos (EVANS, 2012, pp. 104-116) quanto no período posterior de fins da década de 30, quando estes foram reorganizados e colocados sob a autoridade da SS. (CAZENAVE,

\footnotetext{
${ }^{11}$ No original, "[...] Theoretically camp headquarters had to apply for confirmation from Berlin when corporal punishment was to be administrated, and the camp physician had to certify that the prisoner was in good health. Down to the end, however, the procedure widely practiced in many camps was that the prisoner went to the whipping rack immediately, while on receipt of confirmation from Berlin the punishment was repeated, this time 'officially'". Tradução da autora.
} 


\section{artigos}

\section{Jaqueline Uzai Tavares}

2005, p. 10). A violência arbitrária levada à corte é, portanto, contemporânea aos julgamentos - inclusive no que toca os "homicídios não-oficiais" categorizados e condenados por Morgen. (KOGON, 1950, p.107)

Diante de generalizada brutalidade, é curiosa a preocupação em fazê-la parecer justificável. Os relatórios de campos de concentração não eram públicos recursos de propaganda. Eram dirigidos à própria SS, seus escritórios centrais, ou mesmo aos próprios registros internos de cada localidade. Inspetores de campos tinham como parte de suas funções verificar tais registros. ${ }^{12}$ Esses dispositivos testemunham uma certa atenção com a violência praticada pelos homens da organização, mesmo que o narrado acerca dessas práticas fosse na maior parte do tempo falso e que, de todo esse conjunto de relatos forjados de ações teoricamente não autorizadas, apenas uma parte fosse processada e condenada.

Um segundo problema se apresenta quando tratamos da questão da obediência como fator para estabelecimento dos tribunais. Aqui há mais um sintoma paradoxal desse regime dual: apesar de altamente hierarquizada e autoritária, a estrutura estatal nazista era profundamente fragmentada (CAPLAN, 1993, p. 103). Dotado de um ditador absoluto para o qual o juramento da SS se dirigia diretamente (e que consistia em uma referência moral de comportamento), mas que era, ao mesmo tempo, ausente na tomada de decisão de práticas cotidianas, lan Kershaw caracteriza o regime como systemlessness. (KERSHAW, p.99, 1997). Se a obediência e lealdade ao líder era valor

\footnotetext{
${ }^{12}$ No próprio caso de Buchenwald a figura dos inspetores se faz presente. Já em 1941, o inspetor Josias Waldeck Piemont tentou iniciar uma ação contra Karl Koch por excesso de violência, alimentado também por razões pessoais, mas foi barrado por Himmler, abrindo, porém, um precedente. A ocorrência é um importante exemplo para ilustrar a existência desses dispositivos de controle da violência que eram, porém, aplicados de maneira inconstante, a mercê tanto de disputas pessoais como da relação dos acusados com o alto escalão da SS. In: CAZENAVE, Benoît. L'exemplarité du commandant SS Karl Otto Koch, pp. 25-27, 2005.
} 


\section{artigos}

Fronteiras criminais no Nazismo: lei e moral nos julgamentos de Konrad Morgen central, bem como o princípio de agir como ele agiria, como isso se desenrola diante da impossibilidade de saber quais seriam suas ações?

Nessa situação, assassinar prisioneiros - sobretudo judeus - poderia ser perfeitamente aceitável, uma vez que o antissemitismo era um dos traços centrais da figura de Hitler, relacionado, em um raciocínio paranoico e racista, com a defesa do próprio povo, que gerara, naquele mesmo momento, uma política estatal de genocídio em escala industrial. O que era prioritário, o princípio de higiene racial, ou a obediência? Agir sem esperar ordens seria insubordinação, ou uma atitude voluntariosa? Se a questão hierárquica é central para o entendimento dos tribunais e seu papel coercitivo dentro da SS, é preciso considerar seu caráter caótico - e a agênca dos subordinados na interpretação dos princípios abstratos que estes juraram obedecer.

“[...] “No caso da SS, os executivos ideológicos da 'vontade do Líder', as tarefas associadas com 'trabalhar para o Líder' ofereciam infinitas oportunidades para iniciativas bárbaras e, com a expansão da instituição, poder, prestígio e enriquecimento."13 (KERSHAW, p. 104, 1997).

\section{Morgen em Buchenwald}

O Campo de Concentração de Buchenwald, nos arredores de Weimar, foi o maior campo dentro das fronteiras do Reich Alemão. Sua zona principal, contando com seus subcampos, abrigou mais de 280.000 prisioneiros. Ao longo de 8 anos, foi responsável pela morte de cerca de 56.000 pessoas ( $20 \%$ do total que passou pelo campo), causadas pelas condições precárias das instalações, tortura, execuções por fuzilamento e

\footnotetext{
${ }^{13}$ No original: "' $[$ [...] In the case of SS, the ideological executive of the 'Führer's will', the tasks associated with 'working towards the Führer' offered endless scope for barbarous initiatives, and with them Institutional expansion, power, prestige, and enrichment." Tradução da autora.
} 


\section{artigos}

Jaqueline Uzai Tavares

experimentos médicos. (BUCHENWALD AND MITTELBAU-DORA MEMORIALS FOUNDATION, p. 1, 2019)

Konrad Morgen foi enviado ao Campo em julho de 1943, a serviço do Escritório da Polícia Criminal do Reich, para investigar suspeitas de desvio de alimentos do campo para venda no mercado negro (MORGEN, 1947c, p. 48). Uma vez lá, a investigação revelou uma rede de corrupção emaranhada ao redor da figura do chefe do campo, SSStandartenführer Karl Otto Koch.

O trabalho de Morgen levou a julgamento, além dos desvios de verba e enriquecimento pessoal, execuções não autorizadas por injeção de fenol (permitidas apenas para eutanásia em situações em que fosse comprovado, pelos parâmetros nazistas, que os pacientes não eram mais dignos de viver), assassinatos, tentativas de assassinatos e falsos relatórios das causas da morte de prisioneiros (incluindo forjas de suicídios e tentativas de fugas). (MORGEN, 1944a, pp.1-3) Os registros de Morgen totalizam 160 prisioneiros mortos pelas injeções, mais cerca de 120 fuzilados em falsas fugas (MORGEN, 1944b, p.1), não chegando a 300 vítimas, cerca de 0,6\% de todas as mortes ocorridas ao longo dos anos no campo.

As investigações chegam também ao primeiro médico, Waldemar Hoven, responsável pelo hospital e pelas execuções que lá ocorriam, além de outros nomes secundários que são citados como braços de Koch. Ao final das investigações, Koch foi condenado por assassinato e executado. Hoven foi também condenado, mas sua sentença não foi levada a cabo. Devido à escassez de médicos no Reich no período, ele foi liberado e continuou a trabalhar até o fim da guerra. Posteriormente capturado pelos aliados, ele foi julgado em Nuremberg e condenado.

Poderíamos levantar algumas hipóteses do porquê Koch e Hoven terem sido 


\section{artigos}

Fronteiras criminais no Nazismo: lei e moral nos julgamentos de Konrad Morgen levados a julgamento. I. Suas práticas de alguma forma ultrapassaram a brutalidade aceitável pela organização paramilitar genocida? II. Seu comportamento teria de alguma maneira prejudicado o partido? III. Haveria algo de pessoal no tribunal estabelecido contra eles, em mais um sintoma das disputas internas da rígida, mas fragmentada, cadeia de comando nazista?

Quanto à primeira hipótese, é preciso dizer que a punição dos prisioneiros era, em tese, regulamentada pelo Lagerordnung, conjunto de regras criado originalmente em Dachau e depois transplantado para outros campos conforme esses eram passados paras as mãos da SS. Como já posto por Kogon, porém, a violência e a morte eram difundidas mesmo além desta esfera oficial, um problema que não parece exclusivo de Buchewald. Dachau e Sachsenhausen, por exemplo, possuem taxas de mortalidade semelhantes, com 20\% e 14\%, respectivamente (KZ-GEDENSTÄTTE DACHAU, p. 1, 2019) (STIFTUNG BRANDENBURGISCHE GEDENKSTÄTTE GEDENSKTÄTTE UND MUSEUM SACHSENHAUSEN, p. 1, 2019)

O mesmo ocorre quando consideramos os malefícios que Koch poderia estar causando para o regime. Há casos de corrupção e desvios de verba. É preciso considerar, porém, que estes eram difundidos no sistema dos campos (ORTH, 2010, p. 54). De fato, o enriquecimento pessoal fora fator comum, principalmente no alto escalão nazista, desde o começo do regime (EVANS, 2012, pp. 464-470), e Koch não era exatamente um soldado raso. Ainda que seja uma justificativa, não é suficiente para explicar porque ele foi condenado, enquanto tantos outros não.

Quanto às disputas, Koch era uma figura que dividia opiniões de oficiais, tanto superiores quanto subordinados. Era amado por uns e odiado por outros, justamente por sua brutalidade (CAZENAVE, p. 24, 2005). Tal julgamento faz pensar qual era, afinal, 


\section{artigos}

\section{Jaqueline Uzai Tavares}

o comportamento que a SS esperava de seus membros. A violência era, afinal, virtude ou vício?

Igualmente problemático é o papel que a cadeia de comando exercia nessa situação particular. A desobediência poderia ser um fator para condenação, mas o que dizer dos capangas de Koch que poderiam afirmar estar cumprindo ordens do comandante do campo?

“[...] 2. É evidente que os médicos da SS mataram os presos simplesmente ao serem solicitados a fazê-lo pelo comandante do cc (campo de concentração). Se esta prática foi baseada em instruções dadas pelo dr. Grawitz e Himmler é um ponto questionável. Parece que Hoven realizou uma série de assassinatos na crença de que o comandante do campo tinha o direito de pedir sua execução. (MORGEN, 1944d, p. $1)^{14}$

A combinação destes componentes - o excesso de brutalidade, a corrupção, a fragmentação da cadeia de comando e disputas internas - podem ser evocadas para explicar porque eles foram acusados, mas não são claros determinantes do que era julgado. Sobretudo é preciso destacar como cada uma dessas características é parte integral do sistema dos campos. Se todos fossem julgados por esses delitos, que restaria da SS?

Mais do que isso, porém, é preciso destacar uma análise de Morgen sobre os criminosos que passam longe destes critérios - e se aproxima do disparate:

\footnotetext{
${ }^{14}$ No original: "[...] 2. It is apparent that SS doctors killed inmates being simply asked to do so by the cc commandant. Whether this practice was based on instructions given by Dr. Grawitz and Himmler is a questionable point. It appears that Hoven carried out a number of killings in the belief that the cc commandant was quite entitled to ask for their execution [...]". Tradução da autora.
} 


\section{artigos}

Fronteiras criminais no Nazismo: lei e moral nos julgamentos de Konrad Morgen

“[...] O promotor (Morgen) ve em Koch, no chefe da sessão de prisão e no primeiro médico uma gangue de assassinos em série. (MORGENa, 1944, p. 1) 15

Destaque à "gangue de assassinos em série", termo usado por um juiz nazista para julgar seus pares em pleno Holocausto. O absurdo, porém, é um recurso discursivo de diferenciação do tolerável e do intolerável. Nomear alguns como assassinos significa dizer, implicitamente, que todos os outros não são. Ao condenar alguns de seus membros, a SS inocenta o restante. Ao delimitar o que é criminoso, ela também estabelece o que é legal, em uma espécie de legitimidade por contraste.

Tais fronteiras, porém, não são diretamente derivadas de um sistema de crenças claro. Em primeiro lugar, porque seus valores são abstratos. Como colocar a honra em julgamento? O que dizer então da lealdade, em um sistema altamente hierarquizado, mas profundamente fragmentado? Este é o segundo problema: como julgar a obediência quando a autoridade é ambígua, quando o sujeito simultaneamente deve submeter-se cegamente a seus superiores enquanto, abstratamente, "trabalha para o Führer?

E por último, o que dizer quando todo esse constructo de julgamento é descartado diante de uma demanda concreta? A SS, afinal, precisava de médicos. Parece disparatada a preocupação em constituir, em meio a guerra, um tribunal que julgue alguns poucos membros que tenham se excedido no cumprimento da tarefa exploratória e homicida à qual foram designados. Mais estranho é que esta mesma corte não leve suas interpretações até as últimas consequências e capitule diante de demandas práticas que, justamente pela sua urgência, já seriam razão suficiente para

\footnotetext{
${ }^{15}$ No original: "The prosecution [Morgen] sees in Koch, the head of the arrest section and the first physician a gang of mass murders.". Tradução da autora.
} 


\section{artigos}

Jaqueline Uzai Tavares

a inexistência do tribunal.

A imagem que se constitui é a que SS tinha como missão dar satisfações a si mesma - e falhou miseravelmente, em uma espécie de autofagia ideológica. A manutenção do poder nazista se sobrepõe às suas próprias perspectivas morais e legais construídas para legitimá-lo. Nos campos de destruição sua utopia se desmancha justamente ao materializar a realidade cinzenta distópica de seu idealismo. Morgen exemplifica uma crise de consciência em meio ao caos que é, porém, impotente.

A discursividade ambígua dos julgamentos se sustenta apoiada no caráter dual do seu regime e na abstração de seus princípios. A defesa da ordem, da lei e da lealdade precede o ato de determinar a que elas se dirigem. Morgen julga casos que são excepcionais de acordo com o tribunal, mas que tratam, no fundo, de situações generalizadas. Condenam-se homicídios em campos de mortes, através de critérios morais absolutos que podem ser descartados diante de demandas práticas. São feitas análises pessoais que confrontam subconscientemente as violências do Regime sem nunca considerá-lo culpado por tal, que dependem de sua avaliação subjetiva para a legitimação da imoralidade - e que por fim perdem seu sentido criminoso quando mudam as condições de sua ocorrência.

O Estado Dual que se constrói neste cenário é consciente da condicionalidade de sua inflexibilidade. São demandas pragmáticas de uma ideologia utópica, resultado do caráter caótico e fragmentado de um estado centralizado e autoritário. Os tribunais da SS não eram um recurso de propaganda. Eles foram feitos por nazistas para punir nazistas. Ainda que houvessem disputas de poder permeando julgamentos, a preocupação com certos limites comportamentais e a escolha de um tribunal para 


\section{artigos}

Fronteiras criminais no Nazismo: lei e moral nos julgamentos de Konrad Morgen exercê-los demonstra que o uso da normalidade não é mero recurso administrativo externo, e que nem tudo era aceitável - ainda, que, absurdamente, o genocídio em escala industrial fosse.

O regime engendra uma estrutura de comando e de justificativa de poder que se auto-alimenta. Em primeiro lugar, estabelecer preceitos morais a serem seguidos pelos seus oficiais: honra, lealdade, a defesa do povo. Pela natureza de sua legislação, esses princípios são transformados na base de sua lei. Esta, por sua vez, orienta o comportamento dos seus mais engajados oficiais, servindo de guia tanto moral quanto de regulamento para sua atuação. Essa agência, por sua vez, se dá no coração de uma estrutura de poder ao mesmo texto autoritária e fragmentada - em que seguir ordens é de suma importância, mas há uma grande diversidade delas, muitas vezes incompatíveis entre si. Como agir? De acordo com os príncipios pautados pela própria organização - que pautam a obediência. Não há ponto de fuga.

\section{Parâmetros ideológicos da virtude}

Estabelecer quão sinceros são todos estes malabarismos morais e políticos não é tarefa fácil. Entre a vitória aliada, as subsequentes retaliações, os debates contemporâneos, a ambiguidade linguística do Regime, o caráter parcialmente sigiloso do Holocausto e a queima de arquivos, é emaranhado o caminho na busca de adentrar na consciência dos carrascos. O próprio Morgen é nebuloso neste ponto, como já colocado anteriormente.

A mesma incerteza acerca da autoconsciência nazista permeia a história de outras figuras e situações. Do remorso do jurista e Chanceler da Austria Arthur-SeyssInquart diante da condenação em Nuremberg (HOLOCAUST ENCYCLOPEDIA, 2019, p. 


\section{artigos}

Jaqueline Uzai Tavares

1), à resistência ambígua de SS-Obersturmführer Kurt Gerstein, autor de uma série de cartas de denúncia do Holocausto para os aliados enquanto entregava a matéria-prima básica para o funcionamento das câmaras de gás (EVANS, 2012, pp. 640-642), passando por discursos de Himmler assumindo a brutalidade do extermínio (EVANS, 2012, p. 705), o cinismo dos derrotados se mescla ao peso na consciência causado pelo chamado sacrifício.

Sacrifício em nome do que, porém? O que Morgen buscava defender? A lei e a moral são construídas uma sobre a outra. Se condenasse todos que transgrediam os princípios teoricamente colocados no tribunal, não restaria muito da SS. Ao mesmo tempo, porém, zelar por esse constructo era um imperativo moral obrigatório para um bom nazista que, compreendendo as necessidades do corpo social, fará o que for preciso para defendê-lo - mesmo que isso demande sobrepôr-se a outros princípios da própria ideologia.

Esse emaranhado entre lei, da moral e ideologia pode ser visto na entrada do campo. Anunciam os portões de Buchewald: “Certa ou errada - minha pátria”. A devoção à nação se sobrepõe à própria ideia de certo e errado. O nacionalismo não é apenas um princípio político - mas se torna um imperativo moral. 


\section{artigos}

Fronteiras criminais no Nazismo: lei e moral nos julgamentos de Konrad Morgen

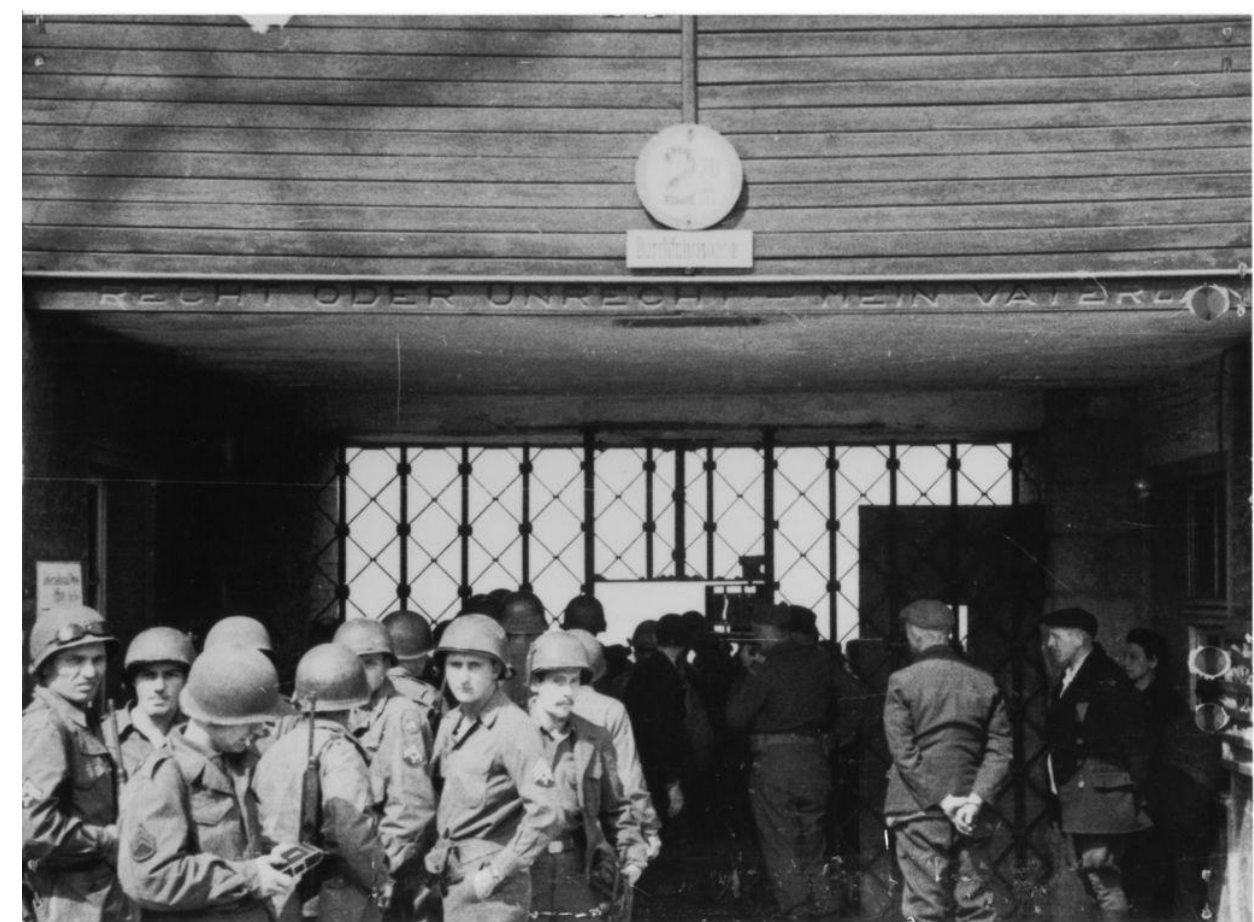

Imagem 3: Entrada do Campo de Concentração de Buchenwald e soldados americanos responsáveis pela libertação do campo, em 1945. Na parte superior, lê-se: "Recht oder unrecht - mein Vaterland". Fonte: Fotoarchive Buchenwald, 2019 


\section{artigos}

\section{Jaqueline Uzai Tavares}

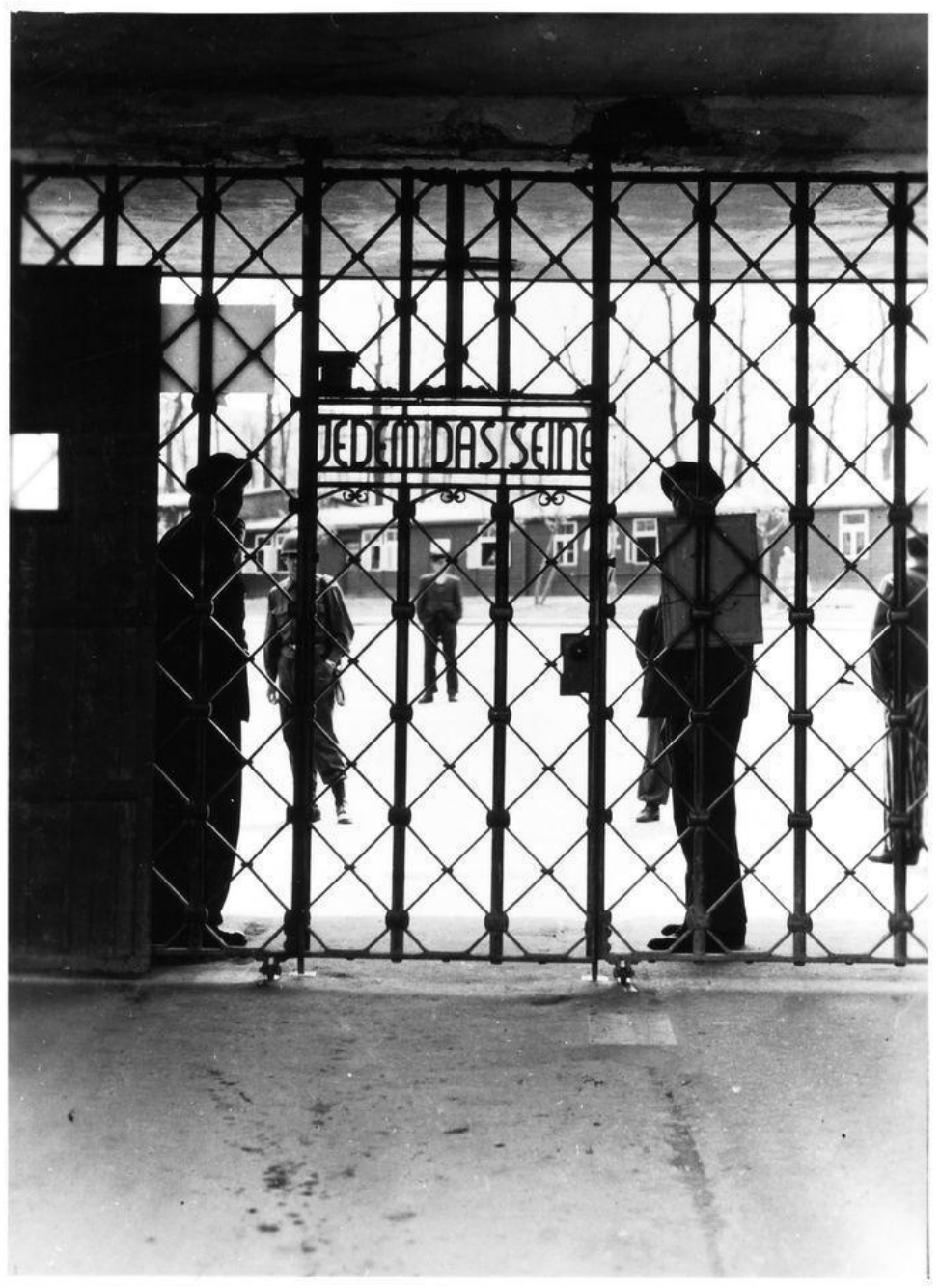

Imagem 2: Detalhe da grade do mesmo portão, também em contexto de libertação, com outra frase "Jeden das Seine". Fonte: Fotoarchive Buchenwald, 2019

"A cada um o seu", anuncia outro portão, um princípio jurídico antigo mobilizado por Aristóteles, referente à divisão de posições na pólis (DE OLIVEIRA, 2019, p. 1). Na porta de um antro de trabalho escravo, não é difícil deduzir seu significado. Cabe os prisioneiros trabalhar e morrer, e aos SS garantir essa ordem. Quaisquer perdas decorrentes diretamente são resultado da "força maior", ou da ordem que comandara as mortes ("mortes legais"). Quanto as baixas que não resultem desses fatores, cabe também a SS julgá-las quando achar necessário. 


\section{artigos}

\section{Fronteiras criminais no Nazismo: lei e moral nos julgamentos de Konrad Morgen}

Se há banalidade no mal desse massacre burocrático, o constructo para justificálo é sofisticado e cuidadoso. As frases refletem os recursos de autojustificativa que permitiam aos responsáveis continuar, seja ao tomar suas ações como um trabalho sujo necessário pela pátria, ou por considerar que as vidas tiradas nesse processo não eram dignas de viver.

Há uma abstração do peso dos crimes cometidos. Ao mesmo tempo, porém, uma busca em justificar o ocorrido como um mal necessário para um fim maior, como na narrativa gloriosa de autossacríficio da SS. São movimentos conscientes, em dois sentidos. Primeiramente, eles são premeditados. Há uma explícita preocupação em propiciar argumentos de justificativa, como forma de continuamente engajar aqueles que já eram parte dos círculos mais internos de ideologia. Dos regulamentos de castigos dos prisioneiros, inspetores de campo, forjas das causas de morte, à limitação da violência e a preocupação em cobri-la com um certo verniz de civilidade - e puni-la quando não de acordo com esses parametros paradoxais.

“[...]8. É dada atenção especial à descrição da maneira desumana (mesmo de acordo com os padrões alemães) pela qual as execuções foram realizadas pelo acusado Koch em Lublin; assassinatos e torturas que ocorreram repetidamente em Lublin são amplamente descritos [...]" (MORGEN, 1944a, p. 2) ${ }^{16}$

Ao mesmo tempo, este engajamento não se dá pela negação do papel da moral. O nazismo recorre à consciência para mobilizar seus seguidores. Seus próprios princípios legais emergem de ideias de virtude, de valores a serem protegidos, de uma

\footnotetext{
${ }^{16}$ No original, "[...] 8. special attention is drawn to the description for the inhumane (even according to German standards) manner in which executions were carried out by the accused Koch in Lublin; murder and torture which repeatedly took place at Lublin is widely described [...]", Tradução da autora
} 


\section{artigos}

\section{Jaqueline Uzai Tavares}

nação a ser resguardada. O próprio Morgen, ao analisar o caso de Hoven, afirma:

“[...] Na minha opinião não há razão para a ZbV-Corte capitular diante desse abuso aparentemente habitual, e diante da pessoa do acusado, para o qual até o especialista dá o mais baixo grau como ser humano e médico.[...]" (MORGEN, 1944c, p.3 $)^{17}$

Não se trata, portanto, apenas de uma análise legal, mas da atribuição de um juízo de valor negativo, uma reflexão derivada da consciência de Morgen instrumentalizada pela SS (e posteriormente descartada).

Um regime de consciência, podemos observar, não implica, porém, em resultados virtuosos - como o Nazismo ilustra de forma caricatural. A filosofia sofisticada, o manejo da lei, os bons recursos de retórica e a consciência moral se fundem às ideologias e projetos concretos defendidos por aqueles que as encarnam. No caso de Morgen, sua condenação dos criminosos - e a recusa de compreendê-los como parte central do sistema a qual ele servia.

Esse amálgama moral atinge tanto ao juiz quanto seus acusados, em uma construção que distribui e neutraliza a responsabilidade dos assassinatos. Morgen, que vê nos acusados assassinos em série, é engrenagem central na reprodução do regime que os dá condições materiais para o homícidio em massa. Os acusados, inocentes e condenados, oscilam em um contexto em que a política de estado ordenava o extermínio e reconfigurava valores de maneira a torná-lo tolerável.

Tais fronteiras criminais, portanto, refletem não apenas a ideia de crime no Reich

\footnotetext{
${ }^{17}$ No original, "[...] In my opinion there is no reason for the court to capitulate before this apparently habitual abuse, and before the person of the culprit, whom even the expert giver the lowest grande as a human beig and physician[...]. Tradução da autora.
} 


\section{artigos}

Fronteiras criminais no Nazismo: lei e moral nos julgamentos de Konrad Morgen e seu papel na autoabsolvição dos funcionários de um estado assassino - mas o fato de que os imperativos morais e dispositivos legais que estes juravam obedecer eram fruto de também de sua própria agência. Morgen é juiz e cúmplice, refém e reprodutor da moral nazista. No fundo, um indíviduo limitado incapaz de frear a máquina nazista, mas fundamental para a sua existência. Nunca poderia, por exemplo, processar Hitler, mas sua mesma atuação nos tribunais é parte da elaboração do próprio constructo ideológico que mantinha o líder no poder.

A figura de Konrad Morgen lança bases para uma discussão que se extende além da moralidade e legalidade de regimes violentos, já bem explorada no campo da teoria do direito. Ele também levanta mais uma problematização acerca de onde se encontra a responsabilidade pelo genocídio no Terceiro Reich. Ao tratar de seus casos, não podemos separar a parte do todo. A lei, a ordem, a hierarquia, os princípios que conduzem os oficiais em direção ao homícidio são por eles mesmos alimentados. Morgen é um oficial da SS, mas subordinado. Alguém que poderíamos chamar de um nazista convicto, de convicção oscilante, porém. Um juiz cujo trabalho e consciência estavam em constante conflito, mas que desempenhou papel ativo dentro do regime. Uma figura que coloca em xeque a força das intenções morais e suas consequências potencialmente nefastas.

Fontes:

-MORGEN, Konrad. Affidavit concerning a German investigation of Oswald Pohl and August Frank on suspicion of mishandling funds during the war. 1947a. Disponivel na internet no endereço: http://nuremberg.law.harvard.edu/documents/4612-affidavitconcerning-a-german?q=konrad+morgen\#p.1, acesso em 22/05/2018.

MORGEN, Konrad. Affidavit concerning experiment with poison at Buchenwald. 1947b. Disponível na internet no endereço: 
https://nuremberg.law.harvard.edu/documents/741-affidavit-concerning-anexperiment?q=konrad+morgen\#p.1, acesso em 01/11/2019

MORGEN, Konrad. Affidavit concerning medical experiments in Buchenwald. 1947c. Disponível na internet no endereço: http://nuremberg.law.harvard.edu/documents/794-affidavit-concerning-medicalexperiments?q=konrad+morgen\#p.1, acesso em 22/05/2018.

MORGEN, Konrad. Affidavit concerning the concentration camp system, including the treatment of inmates, executions and mass extermination, forced marches and secrecy of operations. 1946a. Disponível na internet no endereço, https://nuremberg.law.harvard.edu/documents/5031-affidavit-concerning-theconcentration?q=konrad+morgen\#p.1, acesso em 05/09/2019.

MORGEN, Konrad. Affidavit concerning the selection of prisoners for the typhus experiments. 1947d. Disponível na internet no endereço: http://nuremberg.law.harvard.edu/documents/736-affidavit-concerning-theselection?q=konrad+morgen\#p.1, acesso em 2/05/2018.

MORGEN, Konrad. Affidavit concerning the shipment of prussic acid to the concentration camps. 1947e. Disponível na internet no endereço: http://nuremberg.law.harvard.edu/documents/701-affidavit-concerning-theshipment?q=konrad+morgen\#p.1, acesso em 22/05/2018.

MORGEN, Konrad. Brief against Koch and Dr. Hoven for corrupt practices at Buchenwald. 1944a. Disponível na internet no endereço: http://nuremberg.law. harvard.edu/documents/2327-brief-against-koch-anddr?q=konrad+morgen\#p.1, acesso em 22/05/2018.

MORGEN, Konrad. Extracts from brief against Koch and Dr. Hoven for corrupt practices at Buchenwald. 1944b. Disponível na internet no endereço: http://nuremberg.law.harvard.edu/documents/2329-extracts-from-briefagainst?q=konrad+morgen\#p.1, acesso em 22/05/2018.

MORGEN, Konrad. Opinion of criminal investigator concerning Koch, Dr. Hoven, and others. 1944c. Disponível na internet no endereço: http://nuremberg.law.harvard.edu/documents/2330-opinion-of-criminalinvestigator?q=konrad+morgen\#p.1, acesso em 22/05/2018.

MORGEN, Konrad. Opinion of criminal investigator concerning Koch, Dr. Hoven, and others. 1944d. Disponível na internet no endereço: 
Fronteiras criminais no Nazismo: lei e moral nos julgamentos de Konrad Morgen

http://nuremberg.law.harvard.edu/documents/2331-opinion-of-criminalinvestigator?q=konrad+morgen\#p.1, acesso em 22/05/2018.

MORGEN, Konrad. Trial proceedings: testimony at the International Military Tribunal concerning the Lublin extermination camp. 1946b. Disponível na internet no endereço: http://nuremberg.law.harvard.edu/documents/2337-trial-proceedings-testimony-atthe-international?q=konrad+morgen\#p.1, acesso em 22/05/2018.

Referências bibliográficas:

BROSZAT, Martin. A Plea for the Historicization of National Socialism. In: BALDWIN, Peter (org.). Reworking the past: Hitler, the Holocaust and the Historian's Debate. 1. ed. Boston: BeaconPress, 1990. cap. 4, p. 77-87

BUCHENWALD AND MITTELBAU-DORA MEMORIALS FOUNDATION. Buchenwald Concentration Camp, 1937-1945. In: Buchewald.de. Weimar, 29 dez. 2019. Disponível em: https://www.buchenwald.de/en/72/. Acesso em: 29 dez. 2019

CAPLAN, Jane. National Socialism and the theory of the State. In: CAPLAN, Jane; CHILDRENS, Thomas (Org.). Reevaluating the Third Reich. 1. ed. New Jersey: Holmes\&Meier, 1993. p. 98-113

CAPLAN, Jane; CHILDRENS, Thomas. Introduction. In: CAPLAN, Jane; CHILDRENS, Thomas (Org.). Reevaluating the Third Reich. 1. ed. New Jersey: Holmes\&Meier, 1993. p. 1-19

CAZENAVE, Benoît. L 'exemplarité du commmandt SS Karl Otto Koch. Prix de la Foundation Auschwitz, Pau, France, n. 86, p. 7-58, 2005. Disponível em: http://users.skynet.be/bs136227/src2/Bulletin/86_a.pdf. Acesso em: 15 set. 2019.

KZ-GEDENSTÄTTE DACHAU. Introduction. In: Visitor Information. disponível em: http://www.kz-gedenkstaette-dachau.de/. Acesso em: 24/01/2020.

DE OLIVEIRA, Marcel Thiago. Desenvolvimento do tema da Justiça em Aristóteles. In: Jus. $\quad[S . \quad$ l. $], \quad 3 \quad$ jan. 2020 . Disponível em: https://jus.com.br/artigos/12668/desenvolvimento-do-tema-da-justica-em-aristoteles. Acesso em: 3 Jan. 2020 
-EVANS, Richard J. Terceiro Reich em Guerra. 2a Edição. São Paulo: Planeta, 2012.

EVANS, Richard J. Terceiro Reich no Poder. 2ª Edição. São Paulo: Planeta, 2012.

FRAENKEL, Ernst. The Dual State: A Contribution to the Theory of Dictatorship. 1. ed. Oxford, United Kingdom: Oxford University Press, 2017.

FRASER, David. Criminal Law in Auschwitz: Positivism, Natural Law, and the Career of SS Lawyer Konrad Morgen. In: SKINNER, Stephen (org.). Ideology and Criminal Law: Fascist, National Socialist and Authoritarian Regimes. Oxford: Hart, 2019. p. 33-57.

HACKETT, David A. (Org.). O Relatório Buchenwald: O dia-a-dia em um campo de extermínio nos depoimentos dos sobreviventes. 1. ed. Rio de Janeiro: Record, 1995.

KERSHAW, Ian. The Nazi Dictatorship: problems and perspectives of interpretation. $5^{a}$ edição. Londres: Hodder Arnold, 2000.

KERSHAW, Ian. 'Working towards the Führer: reflections on the nature of the Hitler dictatorship. In: KERSHAW, Ian; LEWIN, Moshe (Org.). Stalinism and Nazism: dictatorships in comparison. 1 ${ }^{\mathrm{a} E d i c ̧ a ̃ o . ~ C a m b r i d g e: ~ C a m b r i d g e ~ U n i v e r s i t y ~ P r e s s, ~} 1997$

MAIER, Charles S. Foreword. In: Jane, CAPLAN; CHILDRENS, Thomas (Org.). Reevaluating the Third Reich. 1. ed. New Jersey: Holmes\&Meier, 1993. p. XI-XVI.

KOGON, Eugene. The theory and practice of hell: the German concentration camps and the system behind them. $1^{\text {a }}$. ed. New York: Farrar, Straus And Giroux, 2006.

ORTH, Karin. The concentration camp personnel. In: CAPLAN, Jane; WASCHMANN, Nikolaus (org.). Concentration Camps in Nazi Germany: The New Histories. New York: Routledge, 2010. cap. 2, p. 44-57.

PAUER-STUDER, Herlind; VELLEMAN, J.D. Konrad Morgen: The Conscience of a Nazi Judge. $1^{\text {a }}$. ed. United Kingdom: Palgrave Macmillan, 2015.

PAUER-STUDER, Herlind. Law and Morality under Evil Conditions: The SS Judge Konrad Morgen. Viena: Jurisprudence 3: 2012, pp. 367-390. Disponível em: http://sammelpunkt.philo.at/2481/.

PUC-SP. Estado de Direito. In: VIEIRA, Oscar Vilhena. Enciclopédia Jurídica da PUCSP: Tomo Teoria Geral e Filosofia do Direito. 1. ed. São Paulo: PUCSP, 1 abr. 2017. Disponível em: https://enciclopediajuridica.pucsp.br/verbete/78/edicao-1/estado-dedireito. Acesso em: 3 Nov. 2019. 


\section{artigos}

Fronteiras criminais no Nazismo: lei e moral nos julgamentos de Konrad Morgen ROBIN, Régine. A memória saturada. 1. ed. Campinas: Unicamp, 2016.

STIFTUNG BRANDENBURGISCHE GEDENKSTÄTTE - GEDENSKTÄTTE UND MUSEUM SACHSENHAUSEN. 1936-1945 Sachsenhausen concentration camp. In: History, Disponível em: https://www.sachsenhausen-sbg.de/en/history/1936-1945sachsenhausen-concentration-camp/. Acesso em: 24/01/2020.

STRAUS, Leo. Natural Right and History. Chicago: University of Chicago Press, 1953.

TRAVERSO, Enzo. The Uniqueness of Auschwitz: Hypotheses, Problems and Wrong Turns in Historical Research. In: Understanding the Nazi Genocide: Marxism after Auschwitz. London: PlutoPress, 1999. cap. 4, p. 63-78.

UNITED STATES HOLOCAUST MEMORIAL MUSEUM. Buchenwald. In: Holocaust Encyclopedia. Washington DC, Disponível em: https://encyclopedia.ushmm.org/content/pt-br/article/buchenwald. Acesso em 29/12/2019

WASCHMANN, Nikolaus. The dynamics of destruction: the development of the concentration camps, 1933-1945. In: CAPLAN, Jane; WASCHMANN, Nikolaus (org.). Concentration Camps in Nazi Germany: The New Histories. New York: Routledge, 2010. cap. 1, p. 17-43.

\section{Imagens:}

Imagem 1: BUCHENWALD AND MITTELBAU-DORA MEMORIALS FOUNDATION. Fotoarchiv Buchenwald, disponível em: http://fotoarchiv.buchenwald.de/detail/249. Acesso 29/12/2019.

Imagem 2: BUCHENWALD AND MITTELBAU-DORA MEMORIALS FOUNDATION. Fotoarchiv Buchenwald, disponível em: http://fotoarchiv.buchenwald.de/detail/290. Acesso 29/12/2019. 